\section{ISO 9001 certification forecasting models}

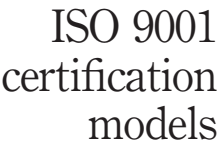

Paulo Sampaio

School of Engineering, Systems and Production Department, University of Minho, Braga, Portugal

Pedro Saraiva

Chemical Engineering Department, University of Coimbra, Coimbra, Portugal, and

António Guimarães Rodrigues

School of Engineering, Systems and Production

Department, University of Minho, Braga, Portugal
Received January 2009

Revised November 2009

Accepted March 2010

\begin{abstract}
Purpose - ISO 9001 certification is nowadays considered to be one of the most effective tools that can be adopted for guiding the management of Quality Systems. The stunning growth observed by these standards all over the world confirms a strong polarization of enterprises' interest in this practice. Owing to the wide incidence of this phenomenon, a deep investigation of ISO 9001 diffusion over time is of mandatory importance. The research here reported covers the development of statistical models in order to characterize the ISO 9001 certification evolution on a country basis, as well as worldwide. Design/methodology/approach - Based on the pioneering results obtained by Saraiva and Duarte, an attempt is now made to: identify clusters of countries, according to their ISO 9001 evolution patterns; characterize the worldwide ISO 9001 certification evolution; identify which are the main evolution perspectives for ISO 9001 diffusion; identify significant variables that may influence ISO 9001 quality management systems diffusion; develop mathematical models in order to characterize the ISO 9001 certification evolution on a country-by-country basis.

Findings - The research carried out allowed one to analyze the worldwide evolution of ISO 9001 certification and suggest new prediction models for the diffusion of quality management systems certification at different geographical realities.

Originality/value - This paper covers the development of statistical models in order to characterize the ISO 9001 certification evolution on a country basis, as well as worldwide.

Keywords ISO 9000 series, Diffusion, Forecasting, Quality management

Paper type Research paper

\section{Introduction}

Quality certification diffusion began when some companies, with the aim of distinguishing themselves, manifested a wish to give an external and formal evidence of their organizational efforts towards quality application. Achieving success in a more and more careful market, their number has progressively grown up in an almost exponential way (Franceschini et al., 2004), even though that is not the case any longer for a significant number of countries, as we will see later on in this paper.
\end{abstract}

The authors acknowledge the financial support provided by Fundação para a Ciência e a Tecnologia (FCT) through a research grant (BD/16032/2004). 
IJQRM

28,1

6
The demand for ISO 9001 certification is achieving an increasingly higher number of organizations, both from the public and private sectors. According to the ISO Survey 2006 (ISO, 2007), by the end of 2006 there were approximately 900000 ISO 9001 certified entities worldwide. Such impressive numbers do indeed make of the ISO 9000 standards an universal and very significant phenomenon, deserving to be studied carefully from several perspectives.

Regardless of previous statistics, there is still a lack of research projects that try to characterize the quality management systems certification evolution and diffusion. Given the large scale of the ISO 9000 phenomenon, it is somewhat surprising that very few quantitative studies of the ISO 9000 dimension across the world seem to have been conducted so far. Some authors have already tried to make an interpretation of ISO 9000 registrations and define a new perspective for their implementation, but an exhaustive analysis of ISO 9000 diffusion is still lacking (Corbett and Kirsch, 2001; Saraiva and Duarte, 2003; Franceschini et al., 2004).

In order to describe the ISO 9001 certification diffusion process, in the present paper a detailed analysis of certification growth worldwide will be reported, using the ISO Survey 2005 (ISO, 2006) as starting point. Based on the pioneering results obtained by Saraiva and Duarte (2003), we will try now to address the following issues:

- Identify clusters of countries, according to their ISO 9001 evolution patterns.

- Characterize the worldwide ISO 9001 certification evolution.

- Identify which are the main evolution perspectives for ISO 9001 diffusion.

- Identify significant variables that may influence ISO 9001 quality management systems diffusion.

- Develop mathematical models in order to characterize the ISO 9001 certification evolution on a country-by-country basis.

First, we will describe the results associated with a cluster analysis performed over the ISO Survey 2005 countries that have reached a value of 0.05 ISO 9001 certificates per 1,000 inhabitants (ISO 9000pc) during the time period that ranges between 1993 and 2005. The aim of this cluster analysis was to identify groups of countries having similar evolution patterns. We have defined the minimum value of 0.05 ISO 9001 certificates per 1,000 inhabitants because we have verified in previous research that below this value we are talking about countries where the ISO 9001 phenomenon is still very limited, and thus would create only background noise when included in our statistical data analysis. According to Figure 1, it is possible to verify the high spread of ISO 9000pc scores across nations, and that there is still a large number of countries with ISO 9000pc scores below 0.05 .

Then, we will show the results that we have obtained regarding the development of mathematical models for describing the behavior found around each cluster of countries identified in the previous phase. The aim of these models is to characterize the ISO 9001 certification evolution over time and forecast the certification market evolution in the forthcoming years.

Therefore, our paper tries to provide a partial answer to the common literature comments pointing out that more and more fact-based and statistically oriented studies should be conducted in this area, and that ISO 9000 standards diffusion studies are still quite scarce. By doing so, we hope to help quality professionals and quality 


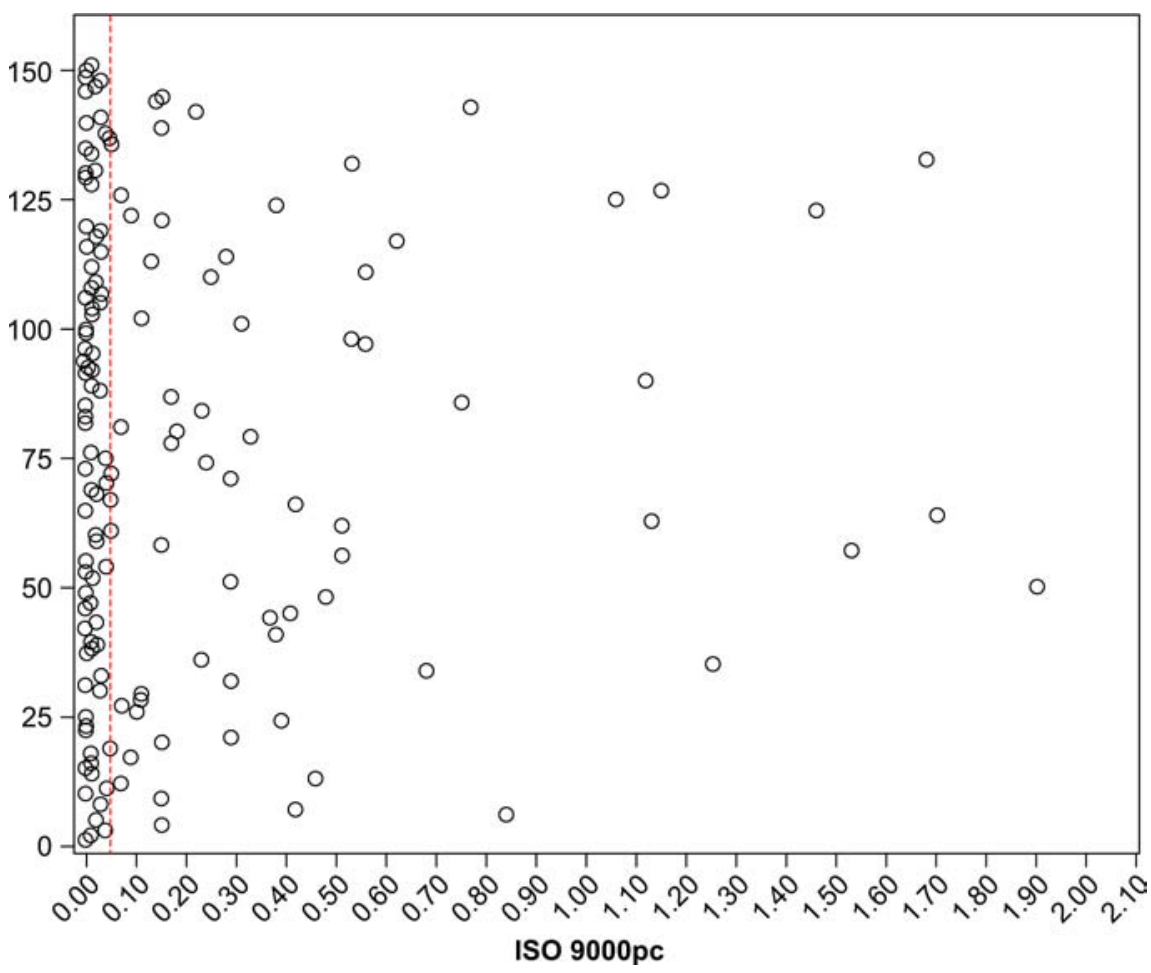

ISO 9001 certification models

Figure 1. ISO 9000pc scores per country

organizations in making better decisions in the future, concerning ISO 9000 standards, by having data evidence to forecast its evolution across time.

\section{Literature review}

Mansfield (1961, cited in Albuquerque et al., 2006) was perhaps the first to explicitly model the process of technology diffusion, using the well-known logistic function and corresponding S-shaped growth curve. Surprisingly, the existing literature on ISO 9000 or ISO 14000 rarely refers the international diffusion literature, despite the fact that the spread of management standards is probably subject to installed-base effects (Albuquerque et al., 2006).

At present, there is a large number of international and national standards whose aim is to order and systematize, among other things, the implementation of business management systems in relation to a wide variety of functions and operations. All the ISO standards have a very similar methodology, which includes the creation, structure and implementation process, possibly followed by a verification conducted by a third independent part.

In December 2006 there were 170 countries with ISO 9001 certified companies, corresponding to 853,478 certifications worldwide (ISO, 2007), and therefore it is relevant to examine how this diffusion came about, and verify if it follows any given specific growth models. 
IJQRM

28,1

For the specific case of diffusion of management standards the literature is scarce. Concerning quality management systems diffusion, one should point out three research teams that have obtained some important results related to this issue. The first results regarding a quantitative approach to explain the ISO 9001 certification diffusion were published by Saraiva and Duarte (2003), who aimed to predict how ISO 9000 certification would develop worldwide in the future. These authors have also identified significant variables that influence the quality management systems certification diffusion. Saraiva and Duarte (2003) have developed a regression model that allows one to compute estimates for ISO 9001 certificates at a given country from its population, gross national income and number of certificates in the last two years. The authors have also derived a model which forecasts the evolution of the total number of certificates issued in the world for the period ranging from 2002 to 2006.

Similarly, a second contribution, carried out by Franceschini et al. (2004, 2006), analyzes in detail some areas looked at by Saraiva and Duarte (2003). The authors have studied the ISO 9000 standard quality certification growth in some European countries and have suggested the use of a logistic model, from a close analogy between certification diffusion and bio-population growth, in order to describe the certification diffusion process related to each specific economic-entrepreneurial macro-structure. The model suggested provides a forecast of new certifications growth, together with the time required to reach a certain saturation level. If we look at the evolution curve for the number of certificates over time, in each country, we can indeed observe a kind of "saturation effect" (Franceschini et al., 2006). According to the authors, after a certain period of fast growth, a physiologic break takes place, suggesting that when the number of certified organizations reaches a certain limit, certification loses its connotation and becomes less attractive for the remaining non-certified companies. At this stage, there is a reduction of the competitive gap between certified and non-certified companies, and the number of new enterprises potentially interested in achieving certification decreases significantly (Franceschini et al., 2004).

Sampaio et al. (2009a, 2009b) have concluded that there is a linear relationship between the number of ISO 9001 issued certificates per 1000 inhabitants and the percentage of ISO 9001 certified companies for each European Union (EU) country. They have also verified that the percentage of certified companies for Italy was equal to 42 percent (2005), a score that is significantly higher than the maximum saturation value forecasted by Franceschini et al. (2004, 2006).

More recently, Marimon et al. (2004) and Casadesús et al. (2005) have tried to see if the model proposed by Franceschini et al. (2004) is only adaptable to a country's ISO 9000 certification, or whether similar models can also be used for their levels of ISO 14000 certifications. Casadesús et al. (2005) have investigated whether these models can be used solely in terms of data gathered at worldwide level or could be also adaptable to each individual country involved. The authors have also tried to find out if the diffusion process has gone on in a relatively homogeneous way, between the different activity sectors involved, or if certification has clearly taken place more quickly in certain sectors. The authors have concluded that, according to the model proposed, ISO 9000 and ISO 14000 standards have reached an important moment in their maturity. From the economic sectors perspective, both standards are developing 
towards smaller indices of concentration and there are fewer fluctuations in the sector's positions in the rankings of certifications. The authors have stated that those sectors that were leaders or pioneers in the introduction of the ISO 9000 standards have played similar galvanizing roles in the case of the ISO 14000 standards. Corbett and Kirsch (2001) have stated that the unprecedented surge in the progress of the ISO 9000 standards has been an important factor in explaining the surge observed for the ISO 14001 standard.

The studies that have been carried out by Corbett are very important and of greater interest to an understanding of ISO 9000 and ISO 14000 certifications diffusion. Nevertheless, those studies refer to the mechanisms of diffusion, rather than to the actual diffusion observed over time (Corbett and Kirsch, 2000; 2001; Corbett, 2005).

Given the above previous works, we will in the next sections provide additional insights related with the diffusion of ISO 9001 certifications, including a cluster analysis of countries and the development of different forecasting models.

\section{Cluster analysis}

Classification is a basic human conceptual activity, and often related also with the previous definition of data clusters. According to Aldenderfer and Blashfield (1984), "cluster analysis" is the generic name for a wide variety of procedures that can be used to create a classification. These procedures empirically form groups of highly similar entities. More specifically, a clustering method is a multivariate statistical procedure that starts with a data set containing information about a sample of entities and attempts to reorganize these entities into relatively homogeneous groups.

The primary goal for the use of cluster analysis is to find groups of similar entities in a sample of data. Seven major families of clustering methods have been developed (Aldenderfer and Blashfield, 1984):

(1) Hierarchical agglomerative.

(2) Hierarchical decisive.

(3) Iterative partitioning.

(4) Density search.

(5) Factor analytic.

(6) Clumping.

(7) Graph theoretic.

Each of these families represents a different perspective on the creation of groups, and the results obtained, when different methods are applied to the same data, can be quite different. We have used an iterative partitioning method, the $k$-means algorithm. Most partitioning methods work in the following fashion (Aldenderfer and Blashfield, 1984):

- Begin with an initial partition of the data set into some specified number of clusters. Then compute the centroids of these clusters.

- Allocate each data point to the cluster that has the nearest centroid.

- Compute the new centroids of the clusters.

- Alternate steps 2 and 3 until no data points change clusters.
ISO 9001 certification models 
IJQRM

28,1

\section{0}

where
According to Branco (2004), the possible number of partitions can computed by (1):

$$
P(n, k)=\frac{k^{n}-\sum_{i=1}^{k-1} \frac{k !}{(k-i) !} P(n, i)}{k !}
$$

$$
\begin{array}{ll}
n & - \text { number of entities. } \\
k & - \text { number of groups. }
\end{array}
$$

The most straightforward way to discover the optimal partition of a data set is to form all possible partitions of such a data set (Aldenderfer and Blashfield, 1984). Since all possible partitions of data sets cannot be examined, researchers have developed a wide range of heuristic procedures that can be used to sample a small subset of all possible partitions in the hope of finding the near optimal partition of a given data set.

In our cluster analysis we have only used data from countries with ISO 9001 certified companies (ISO, 2006) that in the time period that ranges between 1993 and 2005 have reached the value of 0.05 ISO 9001 issued certificates per 1,000 inhabitants (ISO 9000pc). To compare different countries on a similar time scale, removing from the analysis relative delays regarding when ISO 9001 diffusion began to grow at a given country, we have defined an annual time scale that considers $t=0$ for the particular year at which a given country did overcome the ISO 9000pc score of 0.05 .

Based on the previous assumptions, we were able to identify three different clusters of countries that we will briefly describe in the forthcoming paragraphs. Such clusters were defined through a comparison of ISO 9000pc time evolution profiles, according to the common time scale mentioned above.

Cluster 1 is composed of the following countries (Figure 2):

- Czech Republic;

- Hungary;

- Israel;

Figure 2.

ISO 9000pc evolution for Cluster 1 countries

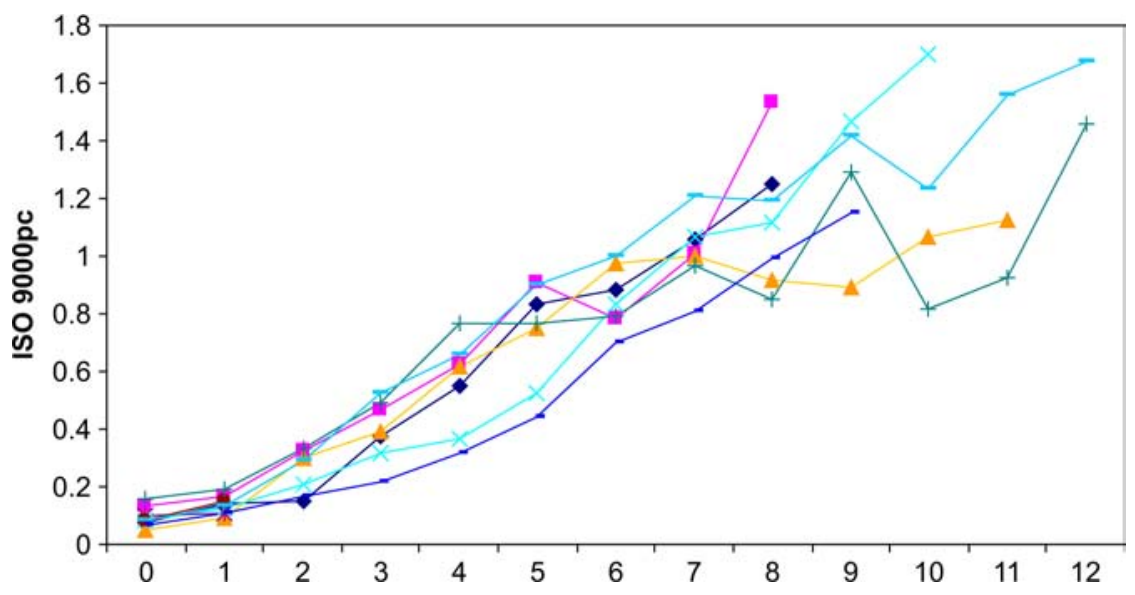


- Italy;

- Oman;

- Serbia;

- Singapore;

- Spain; and

- Switzerland.

As is illustrated in Figure 2, Cluster 1 is composed by countries that are leading the way in terms of ISO 9000pc scores (above 1). Hungary, Italy, Switzerland and Singapore are the countries with the highest ISO 9000pc scores and that are approaching 1.80 certificates per 1,000 inhabitants. This cluster also includes countries that have smoother growth trajectories and present ISO 9000pc values ranging between 1.00 and 1.30, such as the Czech Republic, Spain and Israel.

Cluster 2 comprises 80 percent of the countries included in our sample (Figure 3). Most of these countries correspond to scores of ISO 9000pc below 0.6. They present smoother growth trajectories together with slower growth rates than countries of Cluster 1. However, as is illustrated in Figure 4, Cyprus, Malta and Slovenia are countries in this cluster that present evolution patterns of slow growth, but at a specific time period $t$ they seem to have moved to growth rates similar to the ones associated with Cluster 1 countries.

Cluster 3 comprises Australia, Ireland, Latvia, The Netherlands, New Zealand and the UK.

Most of the Cluster 3 countries belong to the Commonwealth, and their evolution pattern is characterized by a decrease in the number of ISO 9001 certified companies somewhere between 1993 and 2005. As is illustrated in Figure 5, for the majority of these countries, that decrease has occurred in the time of $t=8$ or $t=9$. Figure 6 shows in more detail the Commonwealth countries evolution features.

A common characteristic to the Commonwealth countries is that they have important commercial and economical relationships between them. According to Corbett (2005), companies exporting goods or services into a region may also

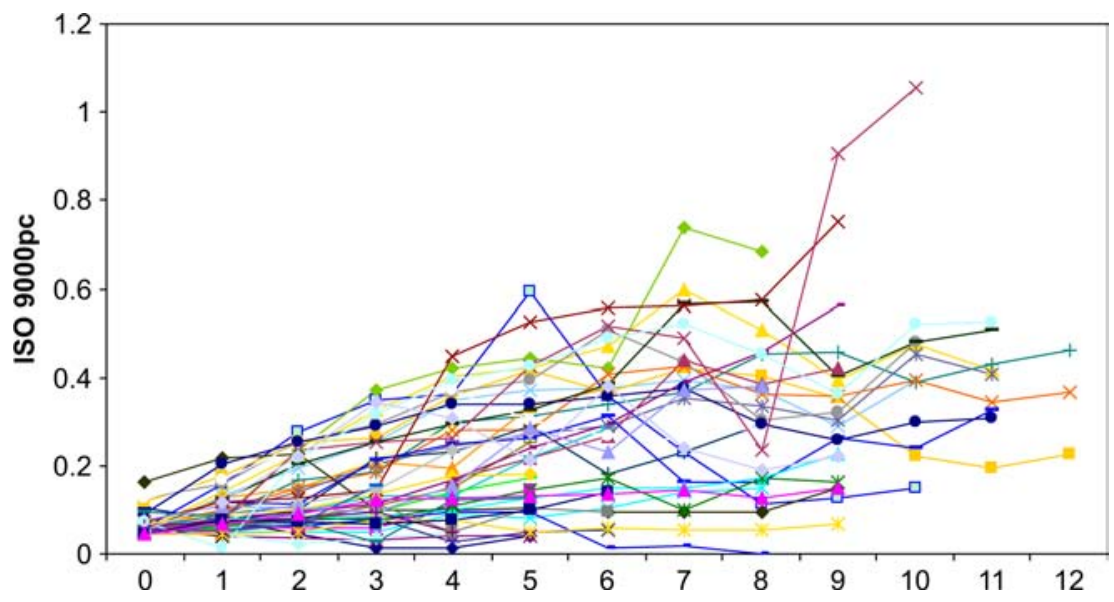

Figure 3. ISO 9000pc evolution for Cluster 2 countries 
IJQRM

28,1

\section{2}

Figure 4.

ISO 9000pc evolution for Cyprus, Malta and

Slovenia

Figure 5.

ISO 9000pc evolution for Cluster 3 countries

Figure 6.

ISO 9000pc evolution for Commonwealth Cluster 3 countries
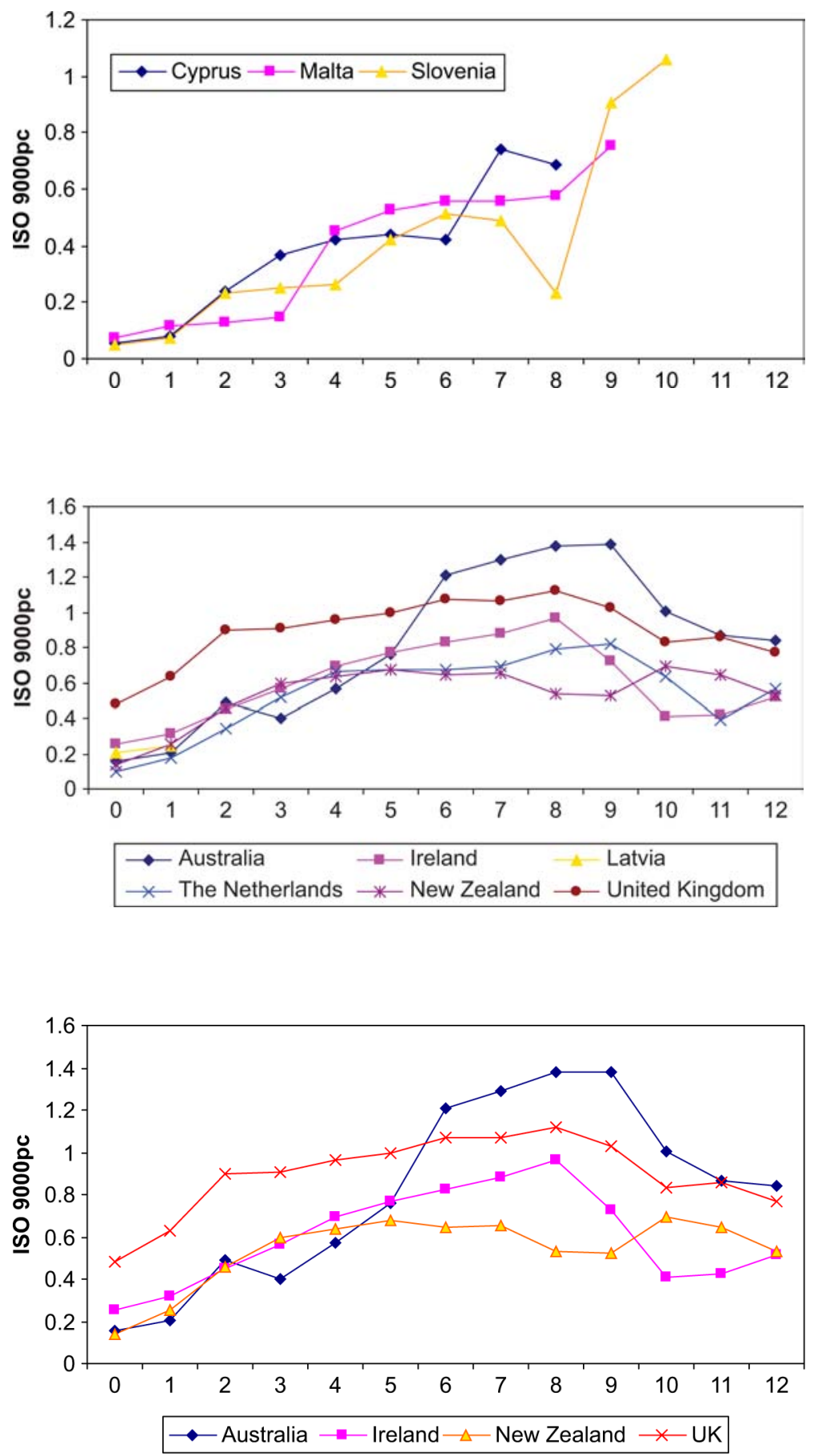
simultaneously import management practices from that region back to their home country. Thus, the quality management systems diffusion in countries may have been significantly influenced by business between them, both in growth and decay of ISO 9000 certifications across time.

According to Figure 6, for $t=8$ (2001) there was a decrease in the number of ISO 9001 certified companies for UK and Ireland. One year after $(t=9,2002)$, a decrease in the number of ISO 9001 Australian certified companies was observed. The same reduction trend happened in New Zealand $(t=10,2003)$ one year after Australia and two years after UK and Ireland. Apparently, the ISO 9001 decrease in the UK and Ireland for 2001 may have contributed two years later to a similar phenomenon in the other countries that have important business relationships with them. One can also point out that the decrease verified in the UK and Ireland occurred one year after the beginning of the transition period for the 2000 version of the ISO 9000 standards.

The diffusion of ISO 9001 certifications started mostly in Europe. Then, European companies pressured their suppliers around the world to become also ISO 9001 certified and such suppliers sought certification as a protection mechanism against the perceived threat of having ISO 9001 certification as an international trade barrier. Next, domestic diffusion started to grow in those countries as well, namely due to competitive reasons (if our competitor is ISO 9001 certified, we should also be so), and pressure exerted by downstream customers through global supply chains (Sampaio et al. 2009b).

The above results do show that the importance of ISO 9001 certification is not the same in all the countries. The number of ISO 9001 entities certified changes from one country to the other, and they can be approached through different time dynamics, with some countries presenting a fast and solid growth, others a slower diffusion, and yet others moving into a decrease, after having reached a maximum number at a certain year.

\section{Forecasting statistical models}

Based on the cluster analysis results introduced in the previous section, we have developed multiple regression models for each cluster of countries, in order to characterize the ISO 9001 certification evolution. As for the variable selection procedure, we have used Backward Stepwise Elimination (Montgomery and Runger, 1994; Reis, 2007; Guimarães and Cabral, 1997).

\subsection{Regression models development}

According to Sampaio et al. (2009a, 2009b), and Saraiva and Duarte (2003), there is an apparent positive relationship between the number of ISO 9001 certified companies per 1,000 inhabitants and countries economic development levels.

As illustrated in Figure 7, we can observe that there is an apparent positive relationship between ISO 9000pc scores and per capita Gross National Income levels (GNIpc) of each country. The majority of the analyzed countries does present ISO $9000 \mathrm{pc}$ values below 0.1 and GNIpc values smaller than $\$$ US 10.000 . However, there are some countries not aligned with this trend. That is the case for countries such as Iceland, USA, Denmark, Norway and Luxembourg, where large values of GNIpc go together with smaller than expected ISO 9000pc scores. 


\section{IJQRM}

28,1

14

\section{Figure 7.}

Relationship between ISO 9000 certification and Gross National Income

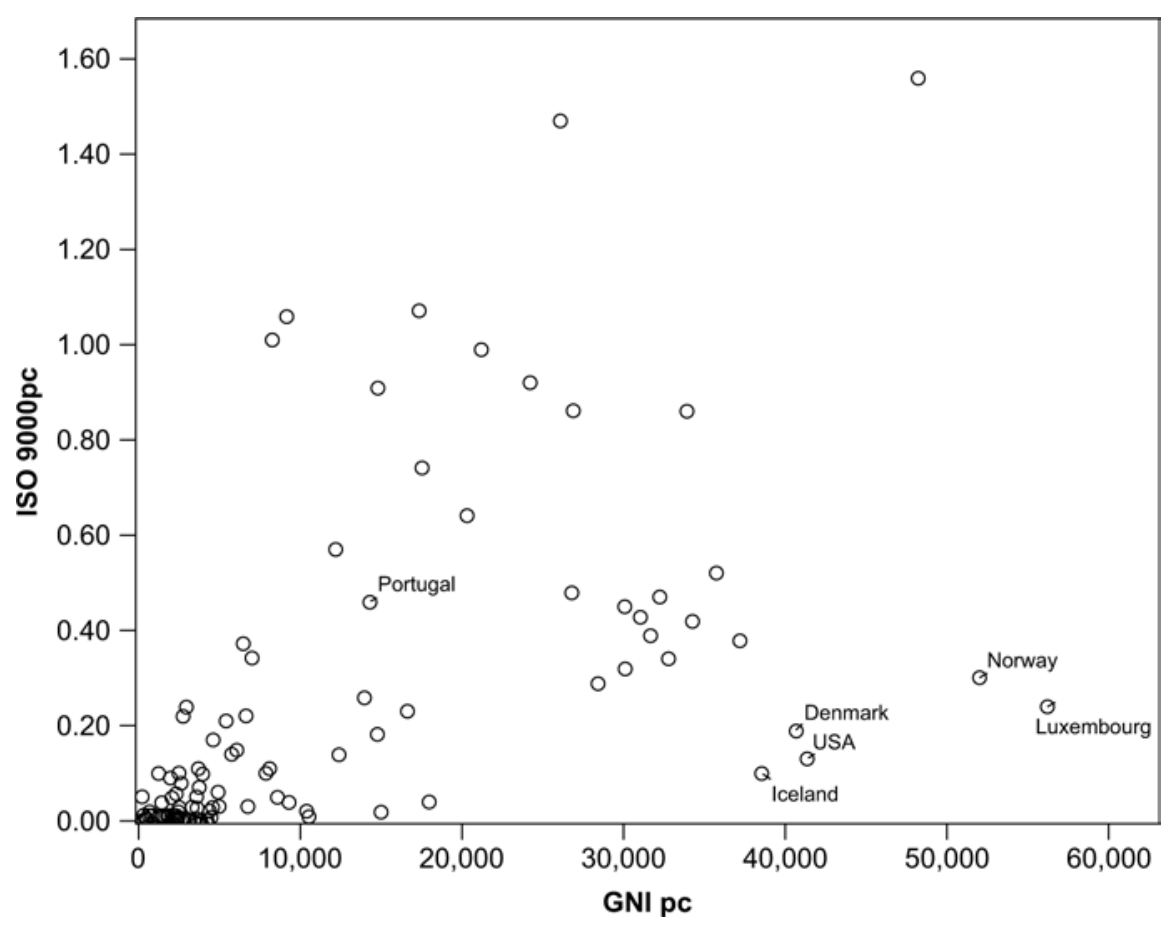

4.1.1 Univariate regression analysis. Based on the previous results, our aim was to develop regression models for each cluster, in order to predict the number of ISO 9001 certificates using information related to the country economic development and number of ISO 9001 issued certificates in the previous years. We would like to point out that we have tested other relationships between the number of ISO 9001 certificates and other economic variables. However, the relationships thus found were not as strong as the one identified between ISO 9000pc scores and countries GNIpc.

We have only used 64 countries from the 2005 Survey (ISO, 2006) for modeling purposes, because only for those ones were we able to find out information related to all the variables used in our models.

In a first step we did analyze the univariate relationships between the dependent variable (ISO 9000pct) and the independent variables (ISO 9000 $\mathrm{pc}_{\mathrm{t}-1}$; ISO 9000 $\mathrm{pc}_{\mathrm{t}-2}$ and GNIpc), including all the countries that have been used for cluster analysis, where we have defined $t=2005, t-1=2004$ and $t-2=2003$.

As a result of this initial univariate analysis, we have identified which of the three initial variables do present a significant relationship with the dependent variable. According to Table I, all the variables should be considered in our model development. Our next step consisted on the development of a multiple linear regression model for each cluster, using the previously selected variables (Table II). For that purpose, we have used as variable selection technique a Backward Stepwise Elimination procedure, leading to the final models described in Tables III-V. 
4.1.2 Multiple regression analysis. In the forthcoming paragraphs we will present the work developed regarding the construction of multiple regression models. In order to improve the models performance we have conducted a quadratic transformation in the independent variable ISO 9000pc and a logarithm transformation in the GNIpc variable, as additional possible model inputs. In multiple regression models, when the assumption of linearity is not met, the usual way of achieving it is to transform the variables into new variables that exhibit more linear relationships with the dependent variable (Makridakis and Wheelwright, 1989). The final resulting models, for each cluster of countries, are the ones mentioned in Tables III-V.

\begin{tabular}{|c|c|c|c|}
\hline Variable & Description & Type & \\
\hline ISO $9000 \mathrm{pc}_{t}$ & $\begin{array}{l}\text { ISO } 9001 \text { issued certificates per } 1,000 \text { inhabitants for } \\
\text { the time period } t\end{array}$ & Continuous & \\
\hline ISO $9000 \mathrm{pc}_{t-1}$ & $\begin{array}{l}\text { ISO } 9001 \text { issued certificates per } 1,000 \text { inhabitants for } \\
\text { the time period } t-1\end{array}$ & Continuous & \\
\hline ISO $9000 \mathrm{pc}_{t-2}$ & $\begin{array}{l}\text { ISO } 9001 \text { issued certificates per } 1,000 \text { inhabitants for } \\
\text { the time period } t-2\end{array}$ & Continuous & Table I. \\
\hline GNIpc & Gross national income per capita & Continuous & Variable descriptions \\
\hline
\end{tabular}

\begin{tabular}{llccccr}
\hline Variable & $\hat{\beta}$ & $\mathrm{SE}(\hat{\beta})$ & $t$ & $p$ value & & \\
\hline ISO 9000pc $t-1$ & 1.134 & 0.034 & 33.712 & $<0.05$ & Sig. & Table II. \\
ISO 9000pc $t-2$ & 1.244 & 0.070 & 17.795 & $<0.05$ & Sig. & Linear regression \\
GNIpc & $8.73 \mathrm{E}-06$ & 0.000 & 2.921 & 0.005 & Sig. & univariate models
\end{tabular}

\begin{tabular}{|c|c|c|c|c|c|c|}
\hline Variable & $\hat{\beta}$ & $\operatorname{SE}(\hat{\beta})$ & $t$ & $p$ value & & \\
\hline $\begin{array}{l}\text { Constant } \\
\left(\text { ISO } 9000 \mathrm{pc}_{t-1}\right)^{2}\end{array}$ & $\begin{array}{l}0.444 \\
0.634\end{array}$ & $\begin{array}{l}0.188 \\
0.141\end{array}$ & $\begin{array}{l}2.362 \\
4.483\end{array}$ & $\begin{array}{l}0.050 \\
0.003\end{array}$ & $\begin{array}{l}\text { N Sig. } \\
\text { Sig. }\end{array}$ & $\begin{array}{r}\text { Multiple regression } \\
\text { model (Cluster 1) }\end{array}$ \\
\hline
\end{tabular}

\begin{tabular}{llcrcrr}
\hline Variable & $\hat{\beta}$ & $\mathrm{SE}(\hat{\beta})$ & $t$ & $p$ value & & \\
\hline Constant & 0.121 & 0.017 & 7.073 & 0.000 & Sig. & Table IV. \\
${\left.\text { (ISO 9000 } \mathrm{pc}_{t-1}\right)^{2}}_{\text {GNI }_{\mathrm{pc}}}^{1.220}$ & 0.078 & 15.733 & 0.000 & Sig. & Multiple regression \\
& $2.10 \mathrm{E}-6$ & 0.000 & 3.061 & 0.004 & Sig. & model (Cluster 2) \\
\hline
\end{tabular}

\begin{tabular}{lrrrrrr}
\hline Variable & $\hat{\beta}$ & $\mathrm{SE}(\hat{\beta})$ & \multicolumn{1}{c}{$t$} & $p$ value & \\
\hline Constant & -0.953 & 0.451 & -2.111 & 0.125 & N Sig. & Table V. \\
(ISO 9000pc $\left.\mathrm{pr}_{t-1}\right)^{2}$ & 0.489 & 0.102 & 4.780 & 0.017 & Sig. & Multiple regression \\
$\operatorname{Ln}\left(\mathrm{GNI}_{\mathrm{pc}}\right)$ & 0.132 & 0.046 & 2.872 & 0.064 & N Sig. & model (Cluster 3) \\
\hline
\end{tabular}


IJQRM

28,1

16
The model developed for Cluster 1 presents a coefficient of determination of 0.742 and $R_{\text {Adj }}^{2}$ equal to 0.705 . According to these values, we can state that the model does reasonably fit the data and is able to characterize ISO 9001 certification evolutions for Cluster 1 countries.

According to Table IV, we were also able to develop a quite good model $\left(R^{2}=0.864 ; R_{\text {Adj }}^{2}=0.856\right)$ for Cluster 2 countries, computing ISO 9000pc estimates for year $t$ at a given country from its values of population, gross national income and number of certificates for year $t-1$.

As shown in Table $\mathrm{V}$, a model for Cluster 3 countries was also derived, presenting a coefficient of determination of 0.95 and $R_{\text {Adj }}^{2}$ equal to 0.917 .

It is important to point out that for all of the derived models a fulfillment of the assumptions inherent to multiple regression analysis was confirmed:

- linear relationship between the dependent variable and each of the independent variables;

- constant variance of regression errors;

- residuals independence;

- residuals are approximately normally distributed; and

- there is no strong multicollinearity between independent variables.

The above models mathematical expressions are as follows:

Cluster 1

$$
I S O 9000_{p c(t)}=0.444+0.634^{*}\left(I S O 9000_{p c(t-1)}\right)^{2}
$$

Cluster 2

$$
I S O 9000_{p c(t)}=0.121+1.220^{*}\left(I_{S O 9000} p c(t-1)\right)^{2}+2.10 E^{-6^{*}} G N I_{p c}
$$

Cluster 3

$$
I S O 9000_{p c(t)}=-0.953+0.489^{*}\left(I S O 9000_{p c(t-1)}\right)^{2}+0.132^{*} \operatorname{Ln}\left(G N I_{p c}\right)
$$

4.1.3 Models validation. In order to further test our models forecasting capabilities, we have performed an internal model validation, using cross validation. For that purpose, we have divided all the clusters into three data sets. For Clusters 1 and 3, each group was composed by, respectively, 3 and 2 countries, and for Cluster 2 the groups were of 16,16 , and 17 countries. Furthermore, we have also computed the absolute error related to each country, according to the following equation:

$$
\varepsilon i=|y i-\hat{y} i|
$$

Using the above samples, we have computed the mean error for each cluster, leading to the results found in Table VI.

According to Table VI, the results obtained allow one to conclude that the derived models do present reasonable forecasting capabilities for ISO 9000pc scores. The model developed for Cluster 1 does present a Root Mean Square Error of Cross Validation (RMSECV) of 0.544 and a $\mathrm{Q}^{2}$ of 0.086 . For Clusters 2 and 3 models we have computed a RMSECV and $\mathrm{Q}^{2}$ of, respectively, 0.082 and $0.155,0.109$ and 0.319 . Thus, according to 
Table VI we can state that Cluster 2 and 3 models do present better forecasting capabilities than the Cluster 1 model.

According to Montgomery and Runger (1994), the prediction interval for a future observation, using multiple linear regression, can be derived as:

$$
\begin{gathered}
\hat{y} 0-t \alpha / 2, n-p \sqrt{\hat{\sigma} 2\left(1+x^{\prime} 0\left(\mathrm{X}^{\prime} \mathrm{X}\right)-1 \times 0\right)} \leq Y 0 \\
\left.\leq \hat{y} 0+t \alpha / 2, n-p \sqrt{\hat{\sigma} 2\left(1+x^{\prime} 0\left(\mathrm{X}^{\prime} \mathrm{X}\right)-1\right.} \times 0\right)
\end{gathered}
$$

Using these uncertainty bands, we are able to compute prediction intervals for each country, together with the respective predicted values. Table VII compiles such prediction intervals and predicted values (regarding the end of 2005) for Cluster 1 countries (see Figure 8, Table VIII, Figure 9, Table IX and Figure 10).

\section{ISO 9001 certification in the world: past, present and future}

In this section we will present results related to the development of a model, which tries to predict the number of entities certified in the world. For that purpose, we have used an exponential smoothing forecasting model (Brown Model). As the Holt Model, the Brown Model should be used for data series that do present a consistent linear trend, without seasonality. However, the most important difference between these two models is that for the Brown Model the smoothing constants should have the same value (Mendenhall et al., 1993).

According to Figure 11, the total number of ISO 9001 certificates in the world has been growing steadily from a total number of 46,571 (December 1993) up to 897,866 (December 2006, last available data when we performed this research). Regardless of

\begin{tabular}{lccc}
\hline & Cluster 1 & Cluster 2 & Cluster 3 \\
\hline$n$ & 9 & 49 & 6 \\
$R^{2}$ & 0.742 & 0.864 & 0.950 \\
$R_{\text {Adj }}$ & 0.705 & 0.856 & 0.917 \\
RMSECV & 0.544 & 0.082 & 0.109 \\
$Q^{2}$ & 0.086 & 0.155 & 0.319 \\
Mean error & 0.244 & 0.062 & 0.038 \\
\hline
\end{tabular}

Table VI.

Model validation results

\begin{tabular}{lcccrr}
\hline Country & $y$ & $\hat{y}$ & LPL & UPL & \\
\hline Czech Republic & 1.25 & 1.16 & 0.33896 & 1.97327 & \\
Hungary & 1.53 & 1.09 & 0.27321 & 1.90777 & \\
Israel & 1.13 & 1.17 & 0.35230 & 1.98693 & \\
Italy & 1.70 & 1.81 & 0.92048 & 2.70713 & \\
Oman & 0.11 & 0.45 & 0.00000 & 1.34207 & Table VII. \\
Serbia & 0.15 & 0.45 & 0.00000 & 1.34027 & Cluster 1 countries: \\
Singapore & 1.46 & 0.98 & 0.15958 & 1.80113 & predicted values and \\
Spain & 1.15 & 1.07 & 0.24740 & 1.88285 & prediction intervals \\
Switzerland & 1.68 & 1.99 & 1.05278 & & \\
\hline
\end{tabular}


IJQRM

28,1

\section{8}

Figure 8.

Cluster 1: observed values versus forecast values (December 2005)

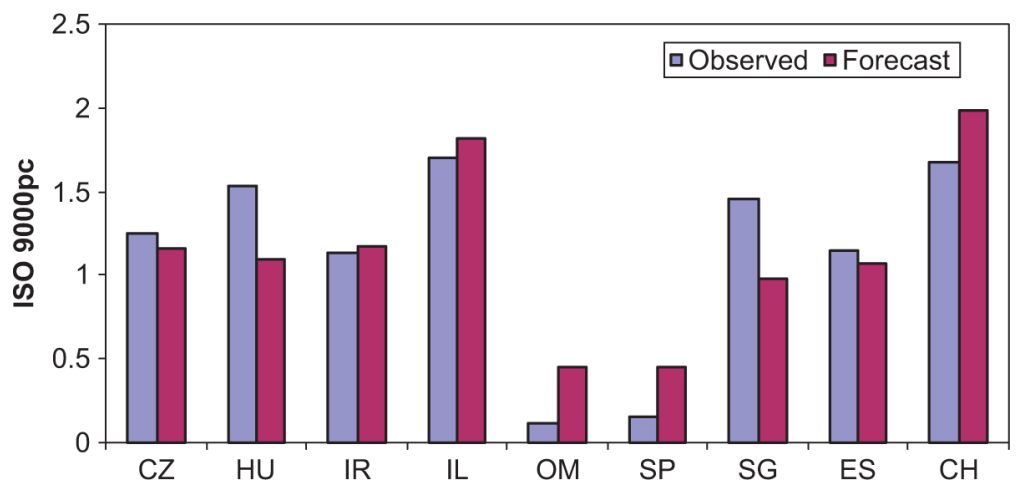

the smaller growth rate that has been verified between 2002 and 2003, one can conclude that on a consolidated basis the overall number of ISO 9001 certificates is still growing and far from reaching any sort of saturation limit on a worldwide basis, even though that is not the case for a number of countries, as we have already seen in previous sections.

Using the data available from 1993 to 2006, a statistical model was developed, and then applied to forecast an evolution for the total number of ISO 9000 certificates in the world from 2007 to 2010, assuming that no discontinuities will occur and also that no global saturation limits will be approached before 2010 .

For time series with linear trends, one should use a second-order exponential smoothing equation (Mendenhall et al., 1993), of the type:

$$
\hat{y}_{t+T}=\left(2+\frac{\alpha T}{1-\alpha}\right) S_{t}-\left(1+\frac{\alpha T}{1-\alpha}\right) S_{t}(2)
$$

where

$$
S_{t}(2)=\alpha S_{t}+(1-\alpha) S_{t-1}(2)
$$

Statistic $S_{t}(2)$ is called the double-smoothed statistic. It gives an indication of the trend for the averages $S_{t}$ over time. Hence, its inclusion in the model will account for a linear trend of $y_{t}$ with time (Mendenhall et al., 1993). The corresponding results thus found are reported in Tables $\mathrm{X}$ and XI.

One should point out that when we derived the previous model the last available data were from the ISO Survey 2006 (ISO, 2007). According to Table XII and Figure 12, we were able to predict that the magic number of one million certificates would be reached by the end of year 2007. However, after the publication of the 2007 Survey (ISO, 2008) we are able to verify that this score was not yet reached. According to the survey, there were issued, by the end of 2007, a total number of 951,446 ISO 9001 certificates. However, we must also take into account that a slightly different approach was adopted by ISO regarding the computation of these values for 2007, resulting in values smaller than the equivalent ones for previous years. This reinforces the good forecasts obtained from our model regarding year 2007.

In order to measure the accuracy of the model developed, we have used the following measures (Makridakis and Wheelwright, 1989): 


\begin{tabular}{|c|c|c|c|c|c|}
\hline Country & $y$ & $\hat{y}$ & LPL & UPL & certification \\
\hline Argentina & 0.15 & 0.14 & 0.00000 & 0.30725 & models \\
\hline Austria & 0.42 & 0.47 & 0.30404 & 0.63183 & \\
\hline Bahrain & 0.15 & 0.17 & 0.01322 & 0.33638 & \\
\hline Belarus & 0.07 & 0.13 & 0.00000 & 0.29227 & \\
\hline Belgium & 0.46 & 0.42 & 0.25807 & 0.58457 & 19 \\
\hline Bosnia & 0.09 & 0.13 & 0.00000 & 0.29165 & \\
\hline Brazil & 0.05 & 0.13 & 0.00000 & 0.29170 & \\
\hline Bulgaria & 0.29 & 0.19 & 0.02461 & 0.34935 & \\
\hline Canada & 0.39 & 0.29 & 0.12931 & 0.45434 & \\
\hline Central African Rep. & 0.10 & 0.12 & 0.00000 & 0.28760 & \\
\hline Chile & 0.07 & 0.14 & 0.00000 & 0.29973 & \\
\hline China & 0.11 & 0.14 & 0.00000 & 0.29938 & \\
\hline Colombia & 0.11 & 0.14 & 0.00000 & 0.29814 & \\
\hline Croatia & 0.29 & 0.20 & 0.03490 & 0.35845 & \\
\hline Cyprus & 0.68 & 0.82 & 0.64709 & 0.99987 & \\
\hline Denmark & 0.23 & 0.26 & 0.09739 & 0.43133 & \\
\hline Estonia & 0.38 & 0.28 & 0.11910 & 0.44259 & \\
\hline Finland & 0.37 & 0.34 & 0.17711 & 0.50384 & \\
\hline France & 0.41 & 0.44 & 0.27765 & 0.60420 & \\
\hline Germany & 0.48 & 0.32 & 0.15551 & 0.48112 & \\
\hline Greece & 0.29 & 0.23 & 0.06523 & 0.38792 & \\
\hline Hong Kong & 0.51 & 0.46 & 0.29713 & 0.62278 & \\
\hline Iceland & 0.15 & 0.23 & 0.06320 & 0.39733 & \\
\hline Iran & 0.05 & 0.13 & 0.00000 & 0.29120 & \\
\hline Japan & 0.42 & 0.38 & 0.21509 & 0.54252 & \\
\hline Jordan & 0.05 & 0.13 & 0.00000 & 0.29176 & \\
\hline Korea, Rep. of & 0.29 & 0.24 & 0.07519 & 0.39768 & \\
\hline Kuwait & 0.05 & 0.17 & 0.01099 & 0.33536 & \\
\hline Lithuania & 0.17 & 0.16 & 0.00000 & 0.32146 & \\
\hline Luxemburg & 0.33 & 0.33 & 0.15422 & 0.50366 & \\
\hline Macau & 0.18 & 0.19 & 0.02900 & 0.35193 & \\
\hline Macedonia & 0.07 & 0.13 & 0.00000 & 0.29374 & \\
\hline Malaysia & 0.23 & 0.17 & 0.00413 & 0.32860 & \\
\hline Malta & 0.75 & 0.55 & 0.38000 & 0.71128 & \\
\hline Mauritius & 0.17 & 0.17 & 0.00480 & 0.32919 & \\
\hline Norway & 0.31 & 0.36 & 0.18454 & 0.52700 & \\
\hline Poland & 0.25 & 0.16 & 0.00106 & 0.32509 & \\
\hline Portugal & 0.56 & 0.41 & 0.25048 & 0.57519 & \\
\hline Romania & 0.28 & 0.20 & 0.03670 & 0.36130 & \\
\hline Slovakia & 0.38 & 0.30 & 0.14236 & 0.46647 & \\
\hline Slovenia & 1.06 & 1.17 & 0.96937 & 1.36557 & \\
\hline South Africa & 0.07 & 0.13 & 0.00000 & 0.29659 & \\
\hline Sweden & 0.53 & 0.54 & 0.37135 & 0.70246 & \\
\hline Thailand & 0.05 & 0.14 & 0.00000 & 0.30134 & \\
\hline Trinidad/Tobago & 0.05 & 0.15 & 0.00000 & 0.30760 & \\
\hline Turkey & 0.15 & 0.14 & 0.00000 & 0.29900 & Table VIII. \\
\hline United Arab Emirates & 0.22 & 0.21 & 0.05297 & 0.37642 & Cluster 2 countries: \\
\hline Uruguay & 0.14 & 0.14 & 0.00000 & 0.30449 & predicted values and \\
\hline USA & 0.15 & 0.23 & 0.06719 & 0.39933 & prediction intervals \\
\hline
\end{tabular}


IJQRM

28,1

20

\section{Figure 9.}

Cluster 2: observed values versus forecast values (December 2005)

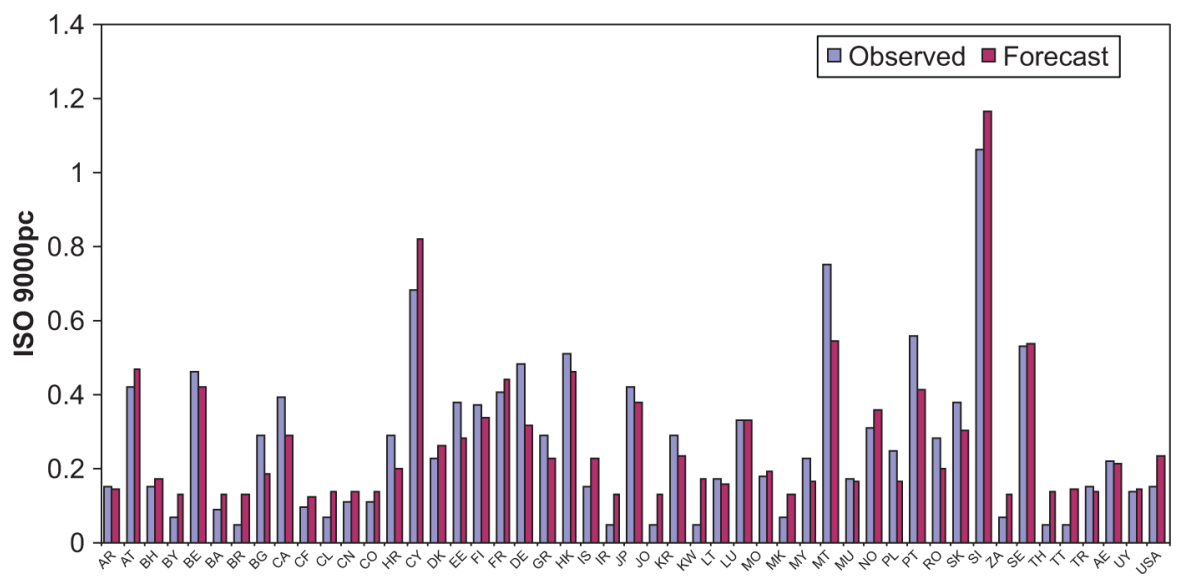

\begin{tabular}{lcccc}
\hline Country & $y$ & $\hat{y}$ & LPL & UPL \\
\hline Australia & 0.84 & 0.78 & 0.54427 & 1.01669 \\
Ireland & 0.51 & 0.53 & 0.29611 & 0.77206 \\
Latvia & 0.24 & 0.23 & 0.00000 & 0.50723 \\
The Netherlands & 0.56 & 0.51 & 0.27395 & 0.74613 \\
New Zealand & 0.53 & 0.59 & 0.37954 & 0.80152 \\
UK & 0.77 & 0.80 & 0.56603 & 1.03574
\end{tabular}

Figure 10.

Cluster 3: observed values versus forecast values (December 2005)

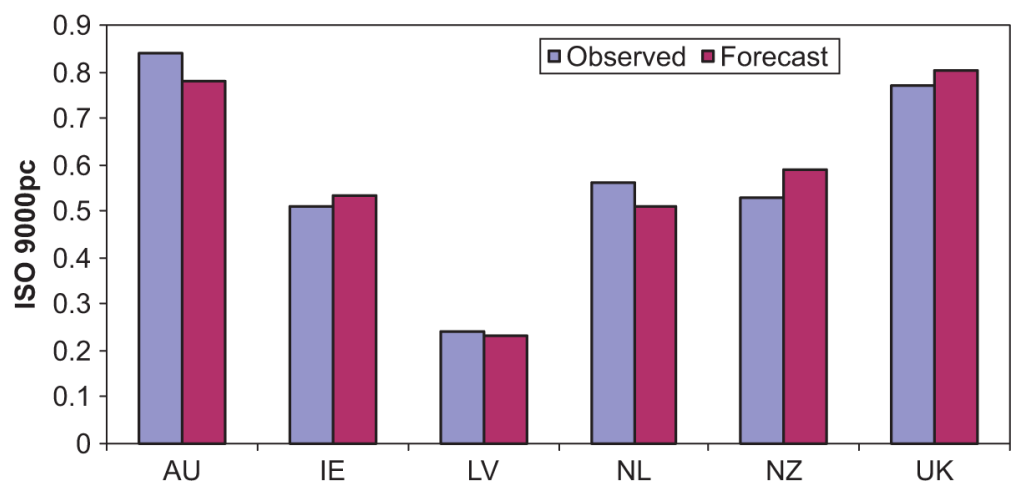

Percentage error (PE) 


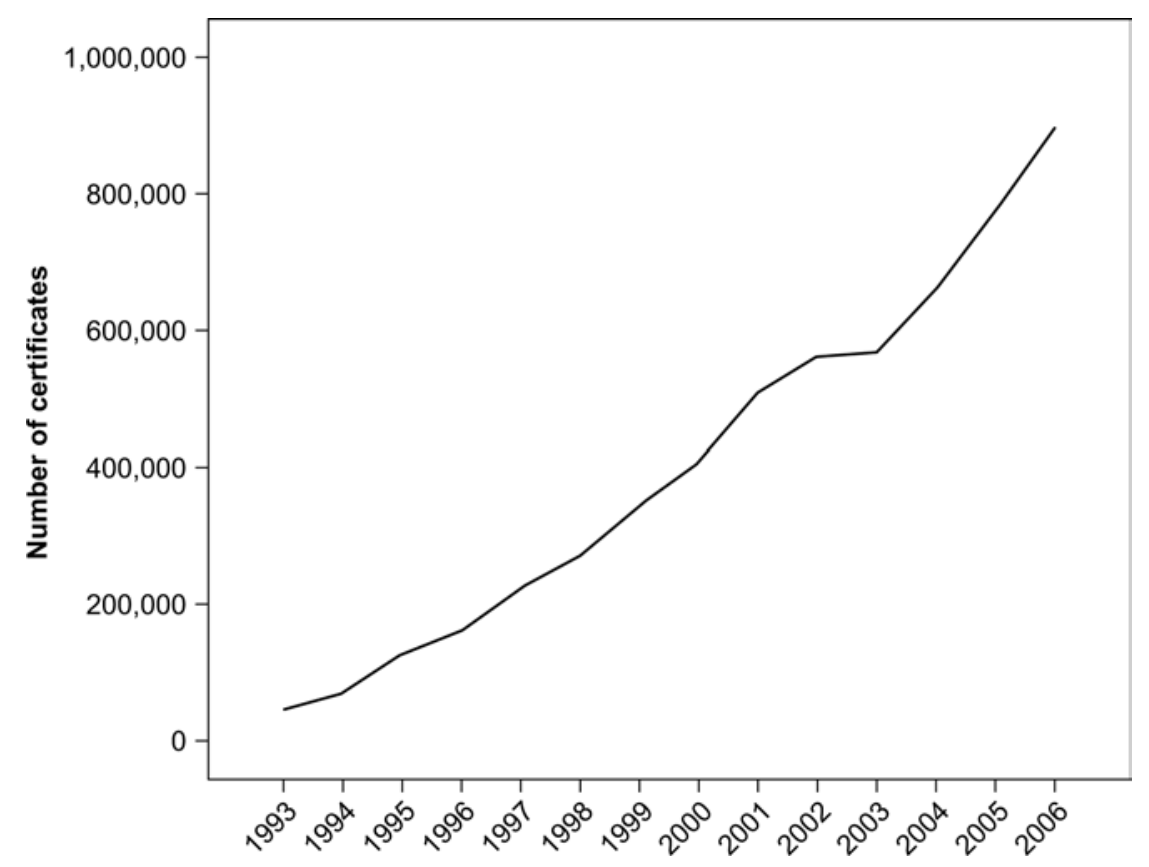

\begin{tabular}{lcccc}
\hline Smoothing constants & Value & SE & $t$ & $p$ value \\
\hline$\alpha$ (Level and Trend) & 0.847 & 0.132 & 6.401 & 0.000
\end{tabular}

\begin{tabular}{lrr}
\hline & & \\
\hline Parameter & Value & \\
\hline$R^{2}$ & 0.983 & Table XI. \\
MAPE (\%) & 8.451 & MaE \\
MAE & 26.672 Model quality parameters \\
\hline
\end{tabular}

Mean absolute percentage error (MAPE)

$$
M A P E=\frac{\sum_{i=1}^{n}\left|P E_{i}\right|}{n}
$$

Mean absolute error (MAE)

$$
M A E=\frac{\sum_{1=1}^{n}\left|e_{i}\right|}{n}
$$

ISO 9001 certification models

21

Figure 11. evolution in the world

Table X. Model parameters ISO 9001 certification 
IJQRM

28,1
22

Table XII.

Observed data of ISO 9001 certificates versus generated values by the Brown Model, together with the corresponding confidence intervals

\begin{tabular}{|c|c|c|c|c|c|}
\hline Year & Observed values & $\begin{array}{c}\text { ISO } 9001 \\
\text { Model estimated values }\end{array}$ & Forecast values & LCL & UCL \\
\hline 1993 & 46,571 & 57,558 & & 0 & 132,723 \\
\hline 1994 & 70,364 & 71,088 & & 0 & 146,254 \\
\hline 1995 & 127,349 & 94,121 & & 18,955 & 169,286 \\
\hline 1996 & 162,701 & 174,117 & & 98,951 & 249,283 \\
\hline 1997 & 223,299 & 202,340 & & 127,174 & 277,506 \\
\hline 1998 & 271,847 & 277,194 & & 202,029 & 352,360 \\
\hline 1999 & 343,643 & 322,530 & & 247,364 & 397,696 \\
\hline 2000 & 408,631 & 408,832 & & 333,666 & 483,998 \\
\hline 2001 & 510,616 & 474,178 & & 399,012 & 549,344 \\
\hline 2002 & 561,747 & 601,411 & & 526,245 & 676,577 \\
\hline 2003 & 567,985 & 625,912 & & 550,746 & 701,077 \\
\hline 2004 & 660,132 & 591,070 & & 515,904 & 666,236 \\
\hline 2005 & 773,867 & 729,715 & & 654,549 & 804,881 \\
\hline 2006 & 897,866 & 875,676 & & 800,510 & 950,842 \\
\hline 2007 & & & $1,016,094$ & 940,928 & $1,091,259$ \\
\hline 2008 & & & $1,134,844$ & 987,045 & $1,282,643$ \\
\hline 2009 & & & $1,253,594$ & $1,019,821$ & $1,487,367$ \\
\hline 2010 & & & $1,372,344$ & $1,040,881$ & $1,703,807$ \\
\hline
\end{tabular}

Figure 12.

Past, present and future for the total number of ISO 9001 certificates in the world

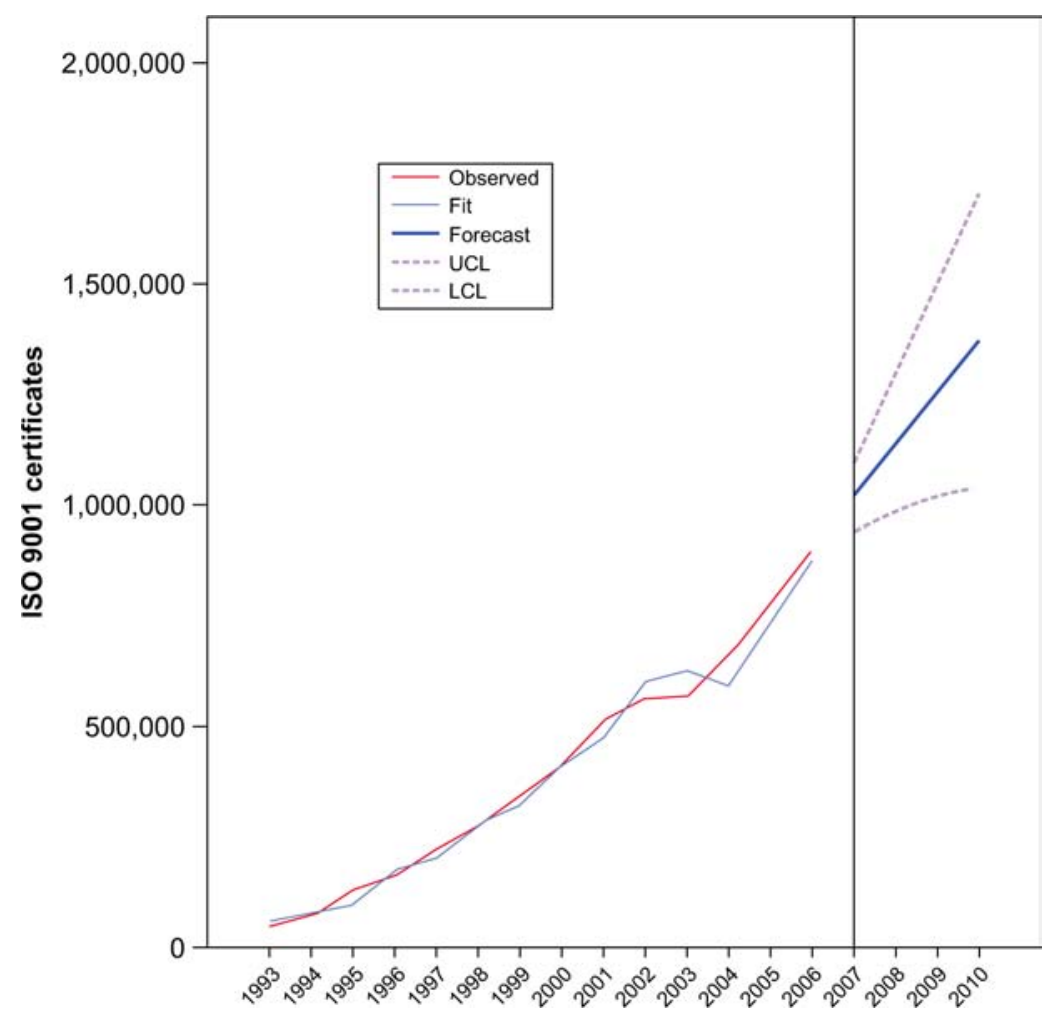


According to Table XI, the model obtained is a quite good one for estimating the number of ISO 9001 issued certificates worldwide. The model coefficient of determination $\left(R^{2}\right)$ is 0,983 , with an associated error of \pm 8 percent, which corresponds to 26,600 certificates.

Comparing our model with the one developed by Saraiva and Duarte (2003), one can see that the mean absolute percentage error for both is close to 10 percent, assuming a score of 10.2 percent for the first model and of 9.7 percent for the second one. The model derived by Saraiva and Duarte presented for $t=2003$ the highest score percentage error (37.8 percent). On the other hand, the model presented in this paper does present for $t=1995$ its highest percentage error value, of 35.3 percent. According to Table XIII we can state that both models do present a quite good accuracy regarding the prediction of the number of ISO 9001 certificates in the world.

\section{Conclusions}

We have presented an analysis of ISO 9001 quality certification growth in the world and in the countries covered by the ISO Survey 2005. For that purpose, we have identified clusters of countries, according to their ISO 9001 evolution curves, and for each cluster generic forecasting models were derived, allowing one to compute estimates for ISO 9001 certificates at a given country from its population, gross national income and number of certificates in the previous years. We have also developed and tested an exponential smoothing model that allows one to predict the total number of certificates issued in the world for the period of time ranging between 2007 and 2010.

As a result of the above efforts, the following mains results can be mentioned:

- The ISO 9000 diffusion in the different countries can be categorized based on their evolution curves. Three clusters of countries have been identified. Cluster 1 is composed by those countries that are leading the way, with the highest

\begin{tabular}{cccccc}
\hline & & & \multicolumn{3}{c}{ PE (ABS) } \\
Year & $\begin{array}{c}\text { Observed } \\
\text { values }\end{array}$ & $\begin{array}{c}\text { Saraiva and Duarte } \\
(2003)\end{array}$ & $\begin{array}{c}\text { Model estimated } \\
\text { values }\end{array}$ & $\begin{array}{c}\text { Saraiva and Duarte } \\
(2003)\end{array}$ & $\begin{array}{c}\text { Model estimated } \\
\text { values }\end{array}$ \\
\hline 1993 & 46,571 & 53,628 & 57,558 & 15.2 & 19.1 \\
1994 & 70,364 & 83,728 & 71,088 & 19.0 & 1.0 \\
1995 & 127,349 & 121,198 & 94,121 & 4.8 & 35.3 \\
1996 & 162,701 & 166,037 & 174,117 & 2.1 & 6.6 \\
1997 & 223,299 & 218,247 & 202,340 & 2.3 & 10.4 \\
1998 & 271,847 & 277,826 & 277,194 & 2.2 & 1.9 \\
1999 & 343,643 & 344,775 & 322,530 & 0.3 & 0.5 \\
2000 & 408,631 & 419,095 & 408,832 & 2.6 & 7.7 \\
2001 & 510,616 & 500,784 & 474,178 & 1.9 & 6.6 \\
2002 & 561,747 & 589,843 & 601,411 & 5.0 & 20.4 \\
2003 & 497,919 & 686,272 & 625,912 & 37.8 & 6.1 \\
2004 & 660,132 & 790,071 & 591,070 & 19.7 & 2.5 \\
2005 & 773,867 & 901,240 & 729,715 & 16.5 & 9.7 \\
2006 & 897,866 & $1,019,778$ & 875,676 & 13.6 & \\
& & & MAPE & 10.2 & \\
\hline
\end{tabular}

ISO 9001 certification models

23 
IJQRM

28,1

\section{4}

If we look at the evolution curve of the number of certificates over time for some countries, we can observe a kind of saturation effect. This phenomenon can be explained by facing the certification process as a distinction element. When the number of certified organizations reaches a certain limit, certification becomes less attractive for the remaining firms and loses its characteristic of differentiation.

We presented an analysis of the ISO 9000 standard diffusion worldwide. We were able to classify countries according to their ISO 9000 evolution pattern and to develop models for each one of such clusters. Furthermore, we have derived a model that allows one to predict the ISO 9000 standard worldwide evolution in the forthcoming years. Our research suggests that there is not an unique forecasting model that could be used in all countries, but that there should be different models, according to the countries ISO 9000 certification evolution patterns.

Additionally, the research presented here has some implications both for academicians and practitioners. For the academic community, this work constitutes an effort to provide an important contribution for studying the ISO 9000 phenomenon diffusion/evolution on a sound statistical basis. For practitioners, particularly certification bodies, this research shows some clues concerning the relationships between some important features and ISO 9001 certification, identifying significant variables that influence ISO 9001 registration evolution and diffusion in the countries analyzed. In addition, these results can help the certification bodies that operate in those countries learn about ISO 9001 evolution trends, and thus predict how the quality management systems certification market will develop in the near future.

Given the economic and social relevance of the ISO 9000 phenomenon, as well as the increasing availability of data related to it, we believe that more and more fact-based and statistically oriented studies should be conducted in this area.

Looking at the obtained results, some questions come out about the ISO 9000 certification evolution. Will the certification market go on? Are there other variables that could influence the ISO 9000 countries diffusion? Are there other statistical models that could better characterize the ISO 9000 evolution?

Some of the issues raised here will continue to deserve additional research and are at the core of the authors' future work. 


\section{References}

Albuquerque, P., Bronnenberg, B. and Corbett, C. (2006), "A spatio-temporal analysis of the global diffusion of ISO 9000 and ISO 14000 certification”, working paper, UCLA Anderson School of Management, UCLA, Los Angeles, 20 June.

Aldenderfer, M. and Blashfield, R. (1984), “Cluster analysis”, Sage University Paper series on Quantitative Applications in the Social Sciences, Sage, Beverly Hills and London.

Branco, J. (2004), Uma Introdução à Análise de Clusters, Sociedade Portuguesa de Estatística, Lisboa.

Casadesús, M., Marimon, F. and Heras, I. (2005), "ISO 9000 and ISO 14000 Standards: an international diffusion model", Proceedings of the TQM \& 6-sigma for Competitiveness Conference, Shanghai, China.

Corbett, C.J. (2005), "Global diffusion of ISO 9000 certification through supply chain", working paper, UCLA Anderson School of Management, UCLA, Los Angeles, 23 August.

Corbett, C.J. and Kirsch, D.A. (2000), "ISO 14000: an agnostic's report from the front line", ISO 9000+ ISO 14000 News, No. 2, pp. 4-17.

Corbett, C.J. and Kirsch, D.A. (2001), "International diffusion of ISO 14000 certification", Production and Operations Management, Vol. 10 No. 3, pp. 327-42.

Franceschini, F., Galetto, M. and Cecconi, P. (2006), "A worldwide analysis of ISO 9000 standard diffusion", Benchmarking: An International Journal, Vol. 13 No. 4, pp. 523-41.

Franceschini, F., Galetto, M. and Gianni, G. (2004), "A new forecasting model for the diffusion of ISO 9000 standard certifications in European countries", International Journal of Quality \& Reliability Management, Vol. 21 No. 1, pp. 32-50.

Guimarães, R.C. and Cabral, J.S. (1997), Estatística - Edição Revista, McGraw-Hill, Lisboa.

ISO (2006), The ISO Survey of Certifications 2005, International Organization for Standardization, Geneva.

ISO (2007), The ISO Survey of Certifications 2006, International Organization for Standardization, Geneva.

ISO (2008), The ISO Survey of Certifications 2007, International Organization for Standardization, Geneva.

Makridakis, S. and Wheelwright, S. (1989), Forecasting Methods for Management, Wiley, Singapore.

Marimon, F., Casadesús, M. and Heras, I. (2004), "A dynamic model for the diffusion of ISO 9000 and ISO 14000 standards", Proceedings of the International Conference on Modelling \& Simulation, Valladolid, Spain.

Mendenhall, W., Reinmuth, J. and Beaver, R. (1993), Statistics for Management and Economics, Duxbury Press, Belmont, CA.

Montgomery, D. and Runger, G. (1994), Applied Statistics and Probability for Engineers, Wiley, New York, NY.

Reis, M.S. (2007), Construção de Modelos de Previsão Baseados em Dados, Universidade de Coimbra, Portugal.

Sampaio, P., Saraiva, P. and Guimarães Rodrigues, A. (2009a), “A statistical analysis of ISO 9000 related data for ultra-peripheral and Portuguese regions", Quality Management Journal, Vol. 16 No. 2, pp. 44-58.

Sampaio, P., Saraiva, P. and Guimarães Rodrigues, A. (2009b), "An analysis of ISO 9000 data in the World and the European Union”, Total Quality Management \& Business Excellence, Vol. 20 No. 12, pp. 1303-20.

Saraiva, P. and Duarte, B. (2003), "ISO 9000: some statistical results for a worldwide phenomenon”, TQM \& Business Excellence, Vol. 14 No. 10, pp. 1169-78.
ISO 9001

certification

models

25 
IJQRM

28,1

26

\section{About the authors}

Paulo Sampaio is Assistant Professor in the Systems and Production Department, University of Minho-Portugal, and R\&D Consultant in the Portuguese Association for Certification. He received a $\mathrm{PhD}$ in Systems and Production Engineering at University of Minho, Portugal, in 2008. His research areas include Quality Management, ISO 9001 Certification, ISO 9000 Standards and Quality Management Systems. Paulo Sampaio is the corresponding author and can be contacted at: paulosampaio@dps.uminho.pt

Pedro Saraiva is Full Professor in the Chemical Engineering Department, University of Coimbra-Portugal. He received his $\mathrm{PhD}$ in Chemical Engineering from the Massachusetts Institute of Technology (MIT), USA, in 1993. At present he is a Member of the Portuguese Parliament. His current research interests include Strategic Management, Innovation, Process Systems Engineering, Applied Statistics and Quality Management.

António Guimarães Rodrigues is Full Professor in the Systems and Production Department, University of Minho-Portugal. He received a $\mathrm{PhD}$ in Production Engineering at Birmingham University, UK, in 1980. His current research includes Management, Simulation and Operational Research. 